\title{
The Effects of Job Crafting on Organizational Citizenship Behavior: Evidence from Egyptian Medical Centers
}

\author{
Amir Shusha ${ }^{1,2}$ \\ ${ }^{1}$ Faculty of Commerce, Damietta University, New-Damietta, Egypt \\ ${ }^{2}$ College of Applied Studies and Community Service, University of Dammam, Kingdom of Saudi Arabia \\ Correspondence: Amir Shusha, Faculty of Commerce, Damietta University, PO box 34519, New-Damietta, \\ Egypt. E-mail: dr.amir_shusha@yahoo.com \& aashousha@ud.edu.sa
}

Received: February 2, 2014

Accepted: March 20, 2014

Online Publication: May 27, 2014

doi: 10.5539/ibr.v7n6p140

URL: http://dx.doi.org/10.5539/ibr.v7n6p140

\begin{abstract}
This article examines the impact of job crafting on organizational citizenship behavior. On the basis of the literature of job crafting and organizational citizenship behavior, the study hypothesized that employees with a job crafting would be most likely to exercise organizational citizenship behavior. Data were collected among 396 nurses and their physician supervisors, who work in nine Egyptian Medical Centers. The results of multiple regression analyses offered a strong support for the proposed model. Nurses with job crafting were most likely to exercise organizational citizenship behavior (altruism, conscientiousness, courtesy, civic virtue and sportsmanship). Therefore, the results confirmed that the task and the relational crafting are predictive variables of organizational citizenship behavior. These findings explored in the light of the job demands-resources model and the job crafting theory. Therefore, the study recommends investigating the mediating role of work engagement, and the moderating role of proactive personality in the relationship between job crafting and its consequences.
\end{abstract}

Keywords: altruism, civic virtue, conscientiousness, courtesy, job crafting, organizational citizenship behavior, relational crafting, sportsmanship, task crafting

\section{Introduction}

In 2001 Wrzesniewski and Dutton introduced the construct of job crafting for the first time. However, the most published studies on job crafting until now are either theoretical or qualitative studies (Tims, Bakker, \& Derks, 2012). From the first appearance of job crafting, it received more attention among researchers and practitioners. The period from 2001 until now has witnessed two very important articles. The first article by Wrzesniewski and Dutton (2001) theorized job crafting and created a new stream for research. The second article by Tims et al. (2012) developed and tested an instrument for measuring job crafting. Their instrument is more likely to play an important role to convert job crafting researches to empirical studies.

A job is a group of tasks and interpersonal relations allocated to an individual in the organization (Ilgen \& Hallenbeck, 1992). Job crafting theory is an alternative perspective to job design theory (Berg, Dutton, \& Wrzesniewski, 2008). Black and Ashford (1995) recognized the role that employees play in the design of their jobs. Organizations design jobs and in turn select people with the right knowledge, skills and abilities for jobs (Campion \& McClelland, 1993). Managers may decide to change something in the jobs, tasks or roles of their employees, in frame of job redesign process (Campion \& McClelland, 1993). Therefore, job design and job redesign are top-down processes, while the job crafting is a down-top process where employees themselves shape their jobs. Therefore, job crafting is considered an important transformation in job design theory (Tims \& Bakker, 2010).

Job crafting is a change process which conducts by employees to alter the task and relational boundaries of their jobs (Wrzesniewski \& Dutton, 2001). According to Wrzesniewski and Dutton (2001); Berg, Dutton and Wrzesniewski (2008) job crafting as a process may occur at the physical and/or cognitive level. Physical level refers to changes make by employees in the shape or ambit of job tasks, whereas cognitive level refers to employees changing their perceptions about their jobs (Bakker, Demerouti, \& Xanthopoulou, 2012).

On the other hand, going beyond what is required is one from important properties of Organizational Citizenship 
Behavior (OCB). Organ (1988, p. 4) defined OCB as "individual behavior that is discretionary, not directly or explicitly recognized by the formal reward system, and that in the aggregate promotes the effective functioning of the organization". He suggested that OCB contains five factors. Altruism is the initiative to help members of the organization in solving work-related problems. Conscientiousness refers to go beyond requirements of job description and comply with organizational rules. Courtesy is to avoid work problems, remind and inform other co-workers in advance. Civic virtue means remaining attentive and proactive when participating in organizational activities. Finally, sportsmanship means tolerating trivial matters without complaining and obeying organizational regulations.

This study contributes to job crafting literature by providing an empirical evidence of how job crafting influences on OCB. In this context, the study tests the effects of job crafting on dimensions of OCB. Previous studies of job crafting were either conceptual or qualitative in nature (Schaufeli \& Taris, 2014). Therefore, this study is one from the first empirical studies in the field of job crafting, and in my knowledge is the first article studies the relationship between job crafting and OCB. Moreover, this study is one of the second wave studies on job crafting, which will pursue the experimental approach to test the theoretical assumptions of the job crafting theory.

In the remainder of this paper, job crafting will be examined by giving an overview of the theories and literature. Also, determinates of OCB will be reviewed in literature, followed by the study model. Then, the methodology used to conduct this research is described, and the results will be presented. Finally, the results will be discussed in the light of the job crafting theories and literature in the discussion section, which also includes the limitations of this research and the implications for further research.

\section{Literature Review}

Literature of the job crafting and the determinants of OCB review and discuss in the following subsections.

\subsection{Literature of the Job Crafting}

Employees themselves commonly formulate and redact their job in order to raise their job satisfaction and well-being. This phenomenon was ignored by researchers for long time (Volman, 2011). But in 2001, Wrzesniewski and Dutton theorized job crafting through their model, which contained four stages. First, employees are motivated to craft their jobs. Second, employees identify the available opportunities to craft their jobs, which modify their motivators to craft their jobs. Third, employees determine and practice one or more techniques to craft their jobs. Finally, crafting practices are associated with outcomes at the level of organization and employee.

Wrzesniewski and Dutton (2001) showed that individual motivation of employees is the main determinant of job crafting. They indicated that employees engage in job crafting because of their needs to control over jobs, create a positive self-image, and connect with others at work. Employees' needs are motivators in job crafting process, but the role of them will depend on to what extent opportunities for job crafting are available at workplace (Berg, Dutton, \& Wrzesniewski, 2008). Opportunities to job crafting mean that employees have got a sense of autonomy in what they do in their jobs and how they do it (Bakker, Demerouti, \& Xanthopoulou, 2012). Opportunities are psychologically positive state because they imply autonomy to act, a sense of possible gain and a sense of ability. Therefore, motivated employees are more likely to assess opportunities for job crafting before crafting their jobs. Thus, perceived opportunities to craft can restrict or open up possibilities for employees to alter their jobs.

Job autonomy is a degree of freedom and discretion allowed to employees over their jobs (Hackman \& Oldham, 1980). Amabile, Hill, Hennessey and Tighe (1994) indicated that jobs with high autonomy make employees to perceive more opportunities to creative and to decide on their own what they are doing. Therefore, job autonomy can restrict or open up opportunities for employees to craft their jobs (Wrzesniewski \& Dutton, 2001). According to Volman (2011), high autonomy jobs engender a certain motivational orientation, which will reflect in job crafting behavior. In this context, Petrou, Demerouti, Peeters and Schaufeli (2012) examined the relationship between work conditions and job crafting among 95 employees from several organizations on a daily basis. They suggested that a work context which characterized by high work pressure and high autonomy has positive effects on job crafting.

Wrzesniewski and Dutton (2001) argued that job crafting practices will extend to the meaning of the job and its identity. Meaning is the degree to which an employee faces positive internal feelings when performing job tasks (Hackman \& Oldham, 1980). Job crafting practices will lead to changing the meaning of the job. These practices will enforce employees' beliefs about the importance of their work (Rosso, Dekas, \& Wrzesniewski, 2010). 
According to Rosso et al. (2010) job meaning is associated with positive work-related outcomes such as increased job satisfaction, improved job performance and inspired motivation. Hackman and Oldham (1980) defined job identity as the degree to which a job requires the completion of a whole and identifiable piece of work with visible outcomes. According to Wrzesniewski and Dutton (2001) job crafting practices will target doing a complete work process from the beginning to the end and will identify a piece of work with a visible outcome, which in turn will enhance job identity. Renn and Vandenberg (1995) suggested that better task identity is associated with better perceived meaningful of work.

Grant and Ashford (2008) defined job crafting as a proactive behavior, which employees may engage to shape their work in order to minimize job demands and maximize job resources. In a sample of 33 employees, Berg, Wrzesniewski and Dutton (2010) elaborated that job crafting as a proactive process is affected by challenges which faced employees. They classified employees into higher and lower adaptive with challenges and explained that high adaptive employees seeing the challenges are located in their expectations while low adaptive employees seeing the challenges are located in their prescribed jobs and/or others expectations of them. Results of Bakker, Tims and Derks (2012) based on 95 employees from various organizations demonstrated that proactive employees were most likely to craft their jobs. They showed also that job crafting was predictive of work engagement and in-role performance. These results were interpreted by the ability of proactive employees to increase their job resources and decrease job demands.

Indeed, job crafting has been shown to influence some of the most important outcomes in organizational studies. According to Tims and Bakker (2010), job crafting may lead to many positive outcomes for the employee as well as for the organization. Job crafting realized positive contributions to job satisfaction, word engagement and employees' perceptions of wellbeing (Berg, Grant, \& Johnson, 2010). Kristof-Brown, Zimmerman and Johnson (2005) showed that job crafting enhances job-employee relationship which is more likely turning to high levels of job satisfaction and positive organizational outcomes, such as organizational commitment and employee's retention. Furthermore, Berg, Dutton and Wrzesniewski (2008) added to these outcomes resilience and thriving in the workplace.

Bakker, Demerouti and Xanthopoulou (2012) reviewed the literature on the relationship between work engagement and job crafting. Their results showed that job crafting is one from crucial factors to stay the state of work engagement. They added that engaged employees taking care of their state of work engagement by proactively shaping their work environment, making full use of the available job resources and creating their own resources to stay engaged. These theoretical conclusions were supported by the study of Tims, Bakker and Derks (2013) which showed that, in three independent samples of Dutch employees, engaged employees were most likely to increase their job resources, mobilize their social network and increase their own job demands in order to create a challenging work environment. Therefore, job crafting may be considered as an effective technique for overcoming work difficulties and even help employees emerging from their work challenges to be more resilient than before.

\subsection{Determinants of Organizational Citizenship Behavior}

Inspire staff to override what is required is a magical tool to achieve organizational effectiveness (Organ, 1990). Organ (1997) decided rethinking about the construct of OCB to distinguish it from extra-role behavior and contextual performance. He described three properties of OCB. First, OCB as discretionary behavior means that it is not required by job description. Second, OCB as behavior is not explicitly associated with the organization's reward system. This does not necessarily mean that OCB must be limited to behavior entirely lacking in any return on the employee. The stabilized exercise of OCB is more likely to create a positive impression about the employee, which turns to recommendation by supervisor for increasing a salary or promotion. Finally, OCB contributes to organizational effectiveness, which means that OCB makes a difference in organizational outcomes.

Organ and Ryan (1995) conducted a meta-analytic review of OCB's determinants. They reviewed 55 studies and concluded that job satisfaction, organizational commitment, perceived fairness and leader supportiveness are robust attitudinal predictors of OCB. With regard to dispositional predictors, their results demonstrated that dispositional variables are not associated with OCB except for conscientiousness.

Podsakoff, Ahearne and MacKenzie (1997) investigated the effects of OCB on the quantity and quality performance. They conducted their study on 218 employees working in 40 paper factories located in the Northeastern of the United State. Their results showed that helping behavior and sportsmanship realized significant positive effects on quantity performance where as helping behavior had a significant negative impact on quality performance, while civic virtue had no effect on quantity or quality performance. 
Podsakoff, Whiting, Podsakoff and Blume (2009) conducted a meta-analytic examination of the relationships among OCB and its consequences at the individual and organizational level. Using 168 independent samples, their results at the individual level indicated that OCB is related to employee performance, reward allocation decisions, withdrawal intentions, employee turnover and absenteeism. Moreover, they showed that, at the organizational level, OCB is related to productivity, efficiency, reduced costs and customer satisfaction.

Van-Dyne and Ang (1998) investigated the impact of both attitudinal commitment and psychological contracts on OCB using a sample of 155 professional workers from a large bank and hospital in Singapore. They indicated that $\mathrm{OCB}$ was stronger for contingent workers than regular employees. This result was interpreted by positive attitudes of contingent workers about their relationship with the organization.

Moorman, Niehoff and Organ (1993) examined the effects of procedural justice, job satisfaction, and organizational commitment on OCB. They conducted their study on 870 employees and 205 of their supervisors in a national television cable company, and demonstrated that procedural justice, job satisfaction and organizational commitment were associated with OCB. Their results indicated also that the relationship between job satisfaction and OCB; and the relationship between organizational commitment and OCB disappeared with controlled procedural justice.

To test the mediating role of perceived organizational support in the relationship between procedural justice and OCB, Moorman, Blakely and Niehoff (1998) explained the effects of procedural justice on OCB by influencing perceived organizational support, which in turn stimulates employees to practice OCB. The study depended on a sample of 157 civilian subordinates and their supervisors from a large military hospital located in Midwestern of the United States and indicated that procedural justice is an antecedent to perceived organizational support, which in turn fully mediates its relationship with OCB. Similar results were reported by Young (2010), who investigated the mediating role of perceived organizational support in the relationship between organizational justice and OCB. His results showed that organizational justice was related to OCB, and perceived organizational support was partially mediated this relationship. This result means that employees' perception of organizational support works as psychological mechanism in relation between organizational justice and OCB.

Asgari, Silong, Ahmad and Samah (2008) investigated the effects of transformational leadership behaviors and organizational justice on $\mathrm{OCB}$ and explored the mediating role of leader-member exchange, perceived organizational support and trust in these relationships. Using a sample of 162 governmental Malaysian employees, their results showed that both of transformational leadership behavior and organizational justice have a positive impact on OCB. Add to that, these relationships were mediated by leader-member exchange, perceived organizational support and trust.

Chiang and Hsieh (2012) examined the causal relationships among perceived organizational support, psychological empowerment and OCB and job performance. Among 513 Taiwan hotels employees, the results indicated that both perceived organizational support and psychological empowerment were positively related to OCB. Also, psychological empowerment and OCB were positively related to job performance. In addition, OCB partially mediated the relationship between both perceived organizational support, and psychological empowerment and job performance.

From the above discussion, this study investigates the following hypotheses:

H1: Altruism is affected by the job crafting dimensions.

$H 2$ : Conscientiousness is affected by the job crafting dimensions.

H3: Courtesy is affected by the job crafting dimensions.

H4: Civic virtue is affected by the job crafting dimensions.

H5: Sportsmanship is affected by the job crafting dimensions.

\section{Methodology}

This section discusses the study sample, its specifications and the measures of job crafting and OCB. Principal component factor analysis and Cronbach's alpha are used to test the validity and reliability of instruments. Finally, descriptive and analysis method are discussed.

\subsection{The Sample}

This study was conducted at 9 hospitals and medical centers affiliated with the University of Mansoura in Egypt. These hospitals and medical centers were Urology and Nephrology Center, Gastroenterology Surgical Center, Mansoura University Hospitals, Emergency Hospital, Specialized Medical Hospital, Mansoura University 
Children's Hospital, Oncology Center and Ophthalmic Center. During the months of July and August 2013, 500 pairs of the questionnaires were distributed to nurses and their physician supervisors. Nurses' questionnaire included questions about gender, educational level, and tenure. It also included a question to assess to what extent they practice task and relational crafting in their jobs. Physicians' questionnaire included one question to assess to what extent their nurses practice OCB in their jobs. Only 412 Nurses-Physicians' questionnaires were retuned by response rate $82 \%$. Due to incomplete data, 16 questionnaires were excluded and so the final response rate was $79 \%$. The nurses' sample was classified according to the respondent's gender into $24 \%$ male and $76 \%$ female; according to respondent's level of education into $40 \%$ less than college degree, $47 \%$ college degree, and $13 \%$ more than college degree; and according to respondent's tenure into $18 \%$ less than or equal 5 years, $43 \%$ more than 5 years and less than or equal 10 years, and 39\% more than 10 years' experience.

\subsection{Measures}

The questionnaire of this study is consists of two instruments job crafting instrument and OCB instrument. Survey design and test the credibility and reliability of the study instruments are discussed as follows:

\subsubsection{Job Crafting Instrument}

From the viewpoint of job demand resources model, Tims et al. (2012) determined four distinct behaviors of job crafting included increasing structural job resources, increasing social job resources, increasing challenging job demands and decreasing hindering job demands. Contrary to that, Wrzesniewski and Dutton (2001) and Berg, Dutton and Wrzesniewski (2008) mentioned that employees can use three forms to craft their jobs. First, employees can modify the boundaries of their jobs by doing more or less tasks, extending or reducing the frame of each task, or changing the methods of task performance. Second, employees can alter the relational boundaries of their jobs by changing the quality or the amount of interaction with others at work. Finally, employees can change the cognitive boundaries of their jobs by modifying their perception about their jobs. However, this study is limited to task and relational crafting because of altering the cognitive boundaries is a changed process in employees themselves not in their job. The second reason to adopt this viewpoint is to achieve consistency between job crafting concept and its measure. Therefore, this study develops and tests an instrument to measure job crafting depending on the instrument of Tims et al. (2012) and the instrument of Volman (2011), which contained two dimensions: task crafting and relational crafting.

Table 1. Factor loading and alpha coefficient of job crafting instrument

\begin{tabular}{lc}
\hline Job Crafting Instrument & $\begin{array}{c}\text { Factor Loading } \\
\text { (Alpha Coefficient) }\end{array}$ \\
\hline Task Crafting & $(0.77)$ \\
I decide on my own how I do job tasks. & 0.61 \\
I try to perform new tasks. & 0.73 \\
I try to make my job tasks more autonomy. & 0.58 \\
I try to change my job tasks. & 0.67 \\
I try to alter the scope of my job tasks. & 0.54 \\
I perform extra tasks even though I do not receive extra salary. & 0.69 \\
I try to get rid of some tasks. & 0.77 \\
Relational Crafting & $(0.72)$ \\
I arrange to work with people from other departments & 0.81 \\
I discuss colleagues about task conflicts. & 0.63 \\
I ask my supervisor to coach me. & 0.59 \\
I ask whether my supervisor is satisfied with my work. & 0.48 \\
I look to my supervisor for inspiration. & 0.71 \\
I ask others for feedback on my job performance. & 0.55 \\
I ask colleagues for advice. & 0.57 \\
\hline & \\
\hline
\end{tabular}


Table 1 presents the results of a principal components analysis and Cronbach's alpha analysis. A principal components analysis was conducted to determine whether the 14-items of job crafting comprise one or more dimensions and to test whether the factor loading of each item exceeds 0.4 or not. The results confirm that the 14 items consist of two factors; task crafting and relational crafting. Add to that, the loading factor of each item is more than 0.4, which is the minimum limit to remain the item in the scale according to Hinkin (1995). A principal components analysis is an essential step because of originality of the scale and the translating process. Then, the study tests scale reliability using Cronbach's alpha coefficient and shows that alpha coefficient of task and relational crafting are successively 0.77 and 0.72 . Therefore, the instruments of each dimension of job crafting are reliable, where they are behind 0.7 which is the minimum limit of scale reliability according to Nunnaly and Bernstein (1994).

\subsubsection{Organizational Citizenship Behavior Instrument}

In 1983, Smith, Organ and Near developed 30 items to measure OCB and used the supervisor report to assess subordinates' OCB within a group of 422 employees in two large banks. Their results supported that OCB had two distinct dimensions altruism and conscientiousness. Organ (1988) suggested that OCB contains more than those two factors. He added courtesy, civic virtue and sportsmanship. Podsakoff and Makenzie (1988) developed 24 items to measure the five dimensions of OCB and tested their instrument of OCB with a large variegated sample. Their results demonstrated that the OCB measure is valid. This study used the instrument of Podsakoff and Makenzie to assess OCB, which contained statements such as "Helps orient new employees even though it is not required" to measure altruism, "Attendance at work is above the norm" to measure conscientiousness, "Considers the impact of his or her actions on coworkers" to measure courtesy, "Attends functions that are not required, but help the company image" to measure civic virtue and "Always finds fault with what the organization is doing" to measure sportsmanship.

\subsection{Statistical Tests}

Table 2 presents the means, standard deviations and correlations among the study variables. The study also depends on hierarchical multiple regression analysis to test the direct effects of task and relational crafting on the dimensions of OCB. The demographic variables which included gender, educational level and tenure are inserted in regression models as control variables. Therefore, Regression model used to test the hypotheses of the study was designed as shown in equation (1).

$$
O C B_{i}=\beta_{0}+\beta_{1} G E N_{i}+\beta_{2} E D U_{i}+\beta_{3} T E N_{i}+\beta_{4} T A S_{i}+\beta_{5} R E L_{i}+u_{i}
$$

Where:

i points to each dimension of $O C B$;

GEN points to gender;

$E D U$ points to the educational level;

$T E N$ points to tenure;

$T A S$ points to task crafting;

$R E L$ points to relational crafting.

\section{Analysis}

The means, standard deviations and correlation coefficients among study variables are presented in Table 2 . The task and relational crafting have a significant positive correlation with all dimensions of OCB. Moreover, control variables such as the educational level and tenure have a significant positive correlation with the two dimensions of job crafting, while the relationship between control variables and dimensions of OCB oscillated from dimension to another.

The regression model is conducted five times according to each dimension of OCB, which are illustrated in table 3. The first regression model determines the influence of each dimension of job crafting on altruism. The fitted model was significant according to the value of $F$ test $(F=59.95, \rho<0.001)$ and the interpreted power of the model was $31 \%$ as represented by $\mathrm{R}^{2}$. The results of this model indicate that relational crafting, task crafting and tenure have a significantly positive effect on altruism. The second regression model, which tests the impact of job crafting dimensions on conscientiousness is also significant $(\mathrm{F}=112.31, \rho<0.001)$. It shows that task crafting is only the significant factor affecting conscientiousness. Moreover, the $\mathrm{F}$ value of the third model indicates that the model is significant $(\mathrm{F}=53.25, \rho<0.001)$. In this case, relational crafting, task crafting, gender and educational level are the main significant determinants of courtesy. Add to that, the results of the forth model show that only 
changes in relational and task crafting are the main significant factors explaining the variations of civic virtue. The final regression model confirms that only relational crafting and educational level have significantly positive impact on sportsmanship.

Table 2. Descriptive statistics: means, standard deviations, and correlation matrix of study variables

\begin{tabular}{|c|c|c|c|c|c|c|c|c|c|c|c|}
\hline Variables & $M$ & $S D$ & 1 & 2 & 3 & 4 & 5 & 6 & 7 & 8 & 9 \\
\hline 1. Gender & 0.32 & 0.46 & & & & & & & & & \\
\hline 2. Educational level & 1.55 & 0.55 & $0.19^{* *}$ & & & & & & & & \\
\hline 3. Tenure & 10.30 & 7.29 & $0.15^{* *}$ & 0.09 & & & & & & & \\
\hline 4. Task crafting & 3.82 & 0.68 & 0.05 & $0.17^{* *}$ & $0.14^{*}$ & & & & & & \\
\hline 5. Relational crafting & 3.56 & 0.79 & 0.04 & $0.12^{*}$ & $0.27^{* *}$ & $0.54^{* *}$ & & & & & \\
\hline 6. Altruism & 3.85 & 0.74 & 0.08 & 0.05 & $0.21^{* *}$ & $0.22^{* *}$ & $0.44^{* *}$ & & & & \\
\hline 7. Conscientiousness & 4.28 & 0.91 & 0.06 & 0.07 & $0.28^{* *}$ & $0.31^{* *}$ & $0.34^{* *}$ & $0.49^{* *}$ & & & \\
\hline 8. Courtesy & 3.89 & 0.88 & $0.11^{*}$ & $0.19^{* *}$ & $0.20^{* *}$ & $0.29^{* *}$ & $0.22^{* *}$ & $0.58^{* *}$ & $0.54^{* *}$ & & \\
\hline 9. Civic Virtue & 3.90 & 0.84 & 0.07 & $0.12^{*}$ & 0.09 & $0.38^{* *}$ & $0.26^{* *}$ & $0.43^{* *}$ & $0.36^{* *}$ & $0.67^{* *}$ & \\
\hline 10. Sportsmanship & 3.81 & 0.92 & 0.05 & 0.08 & 0.6 & $0.40^{* *}$ & $0.28^{* *}$ & $0.36^{* *}$ & $0.34^{* *}$ & $0.55^{* *}$ & $0.47^{* *}$ \\
\hline
\end{tabular}

Note. ${ }^{*} \rho<0.05 ;{ }^{* *} \rho<0.01$.

Table 3. The test of the effects of job crafting on dimensions of OCB

\begin{tabular}{|c|c|c|c|c|c|}
\hline \multirow{2}{*}{ Variables } & Altruism & Conscientiousness & Courtesy & Civic Virtue & Sportsmanship \\
\hline & $\beta^{(\text {Sig. })}$ & $\beta^{(\text {Sig. })}$ & $\beta^{\text {(Sig.) }}$ & $\beta^{(\text {Sig. })}$ & $\beta^{(\text {Sig. })}$ \\
\hline Gender & 0.04 & 0.02 & $0.15^{* *}$ & 0.03 & 0.05 \\
\hline Tenure & $0.15^{* *}$ & 0.03 & 0.068 & 0.02 & 0.09 \\
\hline Education level & 0.05 & 0.02 & $0.12^{*}$ & 0.01 & $0.17^{* *}$ \\
\hline Task crafting & $0.27^{* * *}$ & $0.31^{* * *}$ & $0.26^{* * *}$ & $0.19^{* *}$ & 0.09 \\
\hline Relational crafting & $0.38^{* * *}$ & 0.08 & $0.28^{* * * *}$ & $0.36^{* * *}$ & $0.34^{* * *}$ \\
\hline $\mathrm{R}^{2}$ & 0.31 & 0.40 & 0.29 & 0.27 & 0.31 \\
\hline $\mathrm{F}^{(\mathrm{Sig} .)}$ & $59.95^{* * *}$ & $112.31^{* * * *}$ & $53.25^{* * *}$ & $102.23^{* * *}$ & $52.82^{* * *}$ \\
\hline
\end{tabular}

\section{Discussion}

The study hypothesized that employees with a job crafting would be most likely to engage in OCB, and the results are consistent with this hypotheses. Self-ratings of job crafting have positive impact on supervisor-ratings of OCB. Add to that, the results show that altruism is only affected by task and relational crafting. This result means that if employees have high levels of task and/or relational crafting, they are more likely to be stimulated to engage in altruism behavior toward their co-workers. They drool voluntarily to help new employees, help others who have heavy workloads and are always ready to support people around of them or who have work related problems. The results however demonstrate that conscientiousness is only affected by task crafting. Thus employees who have high levels of task crafting are more likely to engage in conscientiousness behaviors such as obeying organizational roles and preserving the organizational resources.

Moreover, the results confirm that task and relational crafting are the main explanatory variables of courtesy. Therefore, employees seem to respect the rights of others, consider the effect of their action on jobs of others, try to avoid problems with co-workers and take procedural steps to prevent these problems. Furthermore, the results indicate that civic virtue is determined by task and relational crafting. Therefore, employees who have high levels of job crafting engage in civic virtue behaviors such as maintaining the organization image and supporting organizational changes. Finally, sportsmanship is only affected by relational crafting, which means employees 
who have high level of relational crafting are more likely to engage in behaviors such as keen to focus on positive side and to avoid the complaint of trivial matters.

Any job has positive characteristics which are named job resources and negative characteristics which are named job demands. Demerouti, Bakker, Nachreiner and Schaufeli (2001) defined job resources as job aspects that may contribute to achieving work goals, reducing the physiological and psychological costs of job demands and stimulating personal growth. They defined also job demands as job aspects which sustainably exhausted the physical or mental efforts of employees and therefore they associated with physiological and psychological costs. According to Tims et al. (2013), employees influenced their job characteristics and crafted their level of job demands and resources to make their jobs more engaged.

Moreover, when work environment offers many resources, it stimulates workers' willingness to devote their efforts and abilities to their jobs (Schaufeli \& Taris, 2014). Therefore, job resources perform an extrinsic motivational role because they activate the workers' willingness to exert effort and so reducing job demands and enhancing performance (Meijman \& Mulder, 1998). Job resources play an intrinsic motivational role because they satisfy basic human needs for autonomy, relatedness and competence (Schaufeli \& Taris, 2014). In this context, the positive outcomes of job crafting can be interpreted by the favorable psychological state. This state is responsible for the benefit of job resources and reduces the negative effects of job demands. Therefore, the results of this study can be explained by employees' ability to alter their job characteristics through job crafting practices.

According to Wrzesniewski and Dutton (2001), job crafting is a process inspired by employee motivators such as the need of control over job and work meaning, the need of positive self-image and the need of social connection with others. They believe that employees will craft their jobs when the opportunities are available. Therefore, opportunities of job crafting will change job characteristics through alteration process. The alteration process was conducted through changes in the job design and/or changes in the social environment at work. The final goal of these changes is upgrading the quality of the relationship between employees and their jobs which is reflected in positive outcomes such as OCB.

The study sample was selected from 9 hospitals and medical centers; they affiliated to one organization "University of Mansoura" and one sector "health sector". Therefore, additional research should be conducted to test to what extent the study results can be generalized. Moreover, the study variables were measured at the certain point of time, thus the nature of this study is a cross-section. Despite these limitations, the major strength of this paper is that it uses an innovative job crafting scale which concentrated on the theoretical concept itself and excluded cognitive dimension which is a changed process in employees themselves not in their job. Furthermore, this study is one of the first empirical studies in job crafting literature. In the future, I recommend researchers to study the mediating role of work engagement and the moderating role of proactive personality in the relationship between job crafting and its positive outcomes at the level of individuals and organizations. Researchers should also test the validity of job crafting measure in different work environments.

\section{Conclusion}

There has been a growing recognition of the role that employees play in actively altering and changing their task and relational boundaries. Therefore, this study aims to investigate the impact of the job crafting on OCB. The study applied the multiple regression analysis on data collected from 396 nurses and their supervisors working in 9 Egyptian Medical Centers. The results have shown that employees with job crafting are most likely to seem OCB towards their organization and their co-worker. Therefore, the task and relational crafting are predictive variables of OCB. In light of these results, I recommend immediate superiors to create a suitable environment for their subordinates to exercise job crafting, which will lead to many positive outcomes that are reflected in the organizational effectiveness.

\section{References}

Amabile, T. M., Hill, K. G., Hennessey, B. A., \& Tighe, E. M. (1994). The work preference inventory: assessing intrinsic and extrinsic motivational orientations. Journal of Personality and Social Psychology, 66, 950967. http://dx.doi.org/10.1037/0022-3514.66.5.950

Asgari, A., Silong A. D., Ahmad, A., \& Samah, B. A. (2008). The relationship between transformational leadership behaviors, organizational justice, leader-member exchange, perceived organizational support, trust in management and organizational citizenship behaviors. European Journal of Scientific Research, 23(2), 227-242.

Bakker, A. B., Demerouti, E., \& Xanthopoulou, D. (2012). How do engaged employees stay engaged? Ciencia \& 
Trabajo, 14(special issue), 16-22.

Berg, J. M., Grant, A. M., \& Johnson, V. (2010). When callings are calling: Crafting work and leisure in pursuit of unanswered occupational callings. Organization Science, 21, 973-994. http://dx.doi.org/10.1287/orsc.1090.0497

Berg, J. M., Dutton, J. E., \& Wrzesniewski, A. (2008). What is job crafting and why does it matter? Center for Positive Organizational Scholarship, University of Michigan Theory-to-Practice Briefing, 1-8.

Berg, J. M., Wrzesniewski, A., \& Dutton, J. E. (2010). Perceiving and responding to challenges in job crafting at different ranks: When proactivity requires adaptivity. Journal of Organizational Behavior, 31, 158-186. http://dx.doi.org/10.1002/job.645

Black, J. S., \& Ashford, S. J. (1995). Fitting in or making jobs fit: Factors affecting mode of adjustment for new-hires. Human Relations, 48, 421-437. http://dx.doi.org/10.1177/001872679504800407

Campion, M. A., \& McClelland, C. L. (1993). Follow-up and extension of the interdisciplinary costs and benefits of enlarged jobs. Journal of Applied Psychology, 78, 339-351. http://dx.doi.org/10.1037/0021-9010.78.3.339

Chiang, C. F., \& Hsieh, T. S. (2012). The impacts of perceived organizational support and psychological empowerment on job performance: The mediating effects of organizational citizenship behavior. International Journal of Hospitality $\quad$ Management, $\quad 31, \quad 180-190$. http://dx.doi.org/10.1016/j.ijhm.2011.04.011

Demerouti, E., Bakker, A. B., Nachreiner, F., \& Schaufeli, W. B. (2001). The job demands resources model of burnout. Journal of Applied Psychology, 86, 499-512. http://dx.doi.org/10.1037/0021-9010.86.3.499

Grant, A. M., \& Ashford, S. J. (2008). The dynamics of proactivity at work. Research in Organizational Behavior, 28, 3-34. http://dx.doi.org/10.1016/j.riob.2008.04.002

Hackman, J. R., \& Oldham, G. R. (1980). Work Redesign. Reading, MA: Addison-Wesley.

Hinkin, T. (1995). A review of scale development practices in the study of organizations. Journal of Management, 21(5), 967-988. http://dx.doi.org/10.1177/014920639502100509

Ilgen, D. R., \& Hollenbeck, J. R., (1992). The structure of work: Job design and roles. In M. Dunnette \& L. Hough (Eds.), Handbook of industrial and organizational psychology (pp. 165-207). Palo Alto, CA: Consulting Psychologists Press.

Kristof-Brown, A. L., Zimmerman, R. D., \& Johnson, E. C. (2005). Consequences of individuals' fit at work: A meta-analysis of person-job, person-organization, person-group, and person-supervisor fit. Personnel Psychology, 58, 281-342. http://dx.doi.org/10.1111/j.1744-6570.2005.00672.x

Meijman, T. F., \& Mulder, G. (1998). Psychological aspects of workload. In P. J. D. Drenth, H. Thierry, \& C. J. de Wolff (Eds.), Handbook of work and organizational psychology (2nd ed., pp. 5-33). Hove, England: Psychology Press.

Moorman, R. H., Blakely, G. L., \& Niehoff, B. P. (1998). Does perceived organizational support mediate the relationship between procedural justice and organizational citizenship behavior? Academy of Management Journal, 41, 351-357. http://dx.doi.org/10.2307/256913

Moorman, R. H., Niehoff, B. P., \& Organ, D. W. (1993). Treating employees fairly and organizational citizenship behavior: Sorting the effects of job satisfaction, organizational commitment, and procedural justice. Employee Responsibilities and Rights Journal, 6(3), 209-225. http://dx.doi.org/10.1007/BF01419445

Nunnaly, J. C., \& Bernstein, I. H. (1994). Psychometric theory (3rd ed.). New York: McGraw-Hill.

Organ, D., \& Ryan, K. (1995). A meta-analytical review of attitudinal and dispositional predictors of organizational citizenship behaviors. Personnel Psychology, 48, $775-802$. http://dx.doi.org/10.1111/j.1744-6570.1995.tb01781.x

Organ, D. W. (1988). Organizational Citizenship Behavior: The Good Soldier Syndrome. Lexington, MA: Lexington Books.

Organ, W. D. (1997). Organizational citizenship behavior: It's construct clean-up time. Human Performance, 10(2), 85-97. http://dx.doi.org/10.1207/s15327043hup1002_2

Petrou, P., Demerouti, E., Peeters, M. C. W., Schaufeli, W., \& Hetland, J. (2012). Crafting a job on a daily basis: Contextual correlates and the link to work engagement. Journal of Organizational Behavior, 33, 1120 
1141. http://dx.doi.org/10.1002/job.1783

Podsakoff, N. P., Whiting, S. W., Podsakoff, P. M., \& Blume, B. D. (2009). Individual and organizational level consequences of organizational citizenship behaviors: A meta-analysis. Journal of Applied Psychology, 94(1), 122-141. http://dx.doi.org/10.1037/a0013079

Podsakoff, P., Ahearne, M., \& Mackenzie, S. (1997). Organizational citizenship behavior and the quantity and quality of work group performance. Journal of Applied Psychology, 82, 262-270. http://dx.doi.org/10.1037/0021-9010.82.2.262

Podsakoff, P. M., \& MacKenzie, S. B. (1988). The structure of organizational citizenship behavior. Unpublished manuscript, Indiana University, Bloomington, IN.

Renn, R. W., \& Vandenberg, R. J. (1995). The critical psychological states: An underrepresented component in job characteristics model research. Journal of Management, 21, $279-303$. http://dx.doi.org/10.1016/0149-2063(95)90059-4

Rosso, B. D., Dekas, K. H., \& Wrzesniewski, A. (2010). On the meaning of work: A theoretical integration and review. Research in Organizational Behavior, 30, 91-127. http://dx.doi.org/10.1016/j.riob.2010.09.001

Schaufeli, B. W., \& Taris, T. W. (2014). A Critical Review of the Job Demands-Resources Model: Implications for Improving Work and Health. Bridging Occupational, Organizational and Public Health. http://dx.doi.org/10.1007/978-94-007-5640-3_4

Smith, C. A., Organ, D. W., \& Near, J. P. (1983). Organizational citizenship behavior: Its nature and antecedents. Journal of Applied Psychology, 68, 653-663. http://dx.doi.org/10.1037/0021-9010.68.4.653

Tims, M., \& Bakker, A. B. (2010). Job Crafting: Towards a new model of individual job redesign. SA Journal of Industrial Psychology, 36, 1-9. http://dx.doi.org/10.4102/sajip.v36i2.841

Tims, M., Bakker, A. B., \& Derks, D. (2012). The development and validation of the job crafting scale. Journal of Vocational Behavior, 80, 173-186. http://dx.doi.org/10.1016/j.jvb.2011.05.009

Tims, M., Bakker, A. B., \& Derks, D. (2013). The impact of job crafting on job demands, job resources, and well-being. Journal of Occupational Health Psychology, 18, 234-245. http://dx.doi.org/10.1037/a0032141

Van-Dyne, L., \& Ang, S. (1998). Organizational citizenship behavior of contingent workers in Singapore. The Academy of Management Journal, 41(6), 692-703. http://dx.doi.org/10.2307/256965

Volman, M. (2011). Putting the context back in job crafting research: causes of job crafting behavior. Master's thesis, Tilburg University, The Netherlands. Retrieved from http://arno.uvt.nl/show.cgi?fid=115918

Wrzesniewski, A., \& Dutton, J. E. (2001). Crafting a job: Revisioning employees as active crafters of their work. Academy of Management Review, 26(2), 179-201. http://dx.doi.org/10.5465/AMR.2001.4378011

Young, L. D. (2010). Is organizational justice enough to promote citizenship behavior at work? A retest in Korea. European Journal of Scientific Research, 45(4), 637-648.

\section{Copyrights}

Copyright for this article is retained by the author(s), with first publication rights granted to the journal.

This is an open-access article distributed under the terms and conditions of the Creative Commons Attribution license (http://creativecommons.org/licenses/by/3.0/). 